\title{
Validating a widely used measure of frailty: are all sub-components necessary? Evidence from the Whitehall II cohort study
}

\author{
Kim Bouillon • Severine Sabia • Markus Jokela • \\ Catharine R. Gale • Archana Singh-Manoux • \\ Martin J. Shipley • Mika Kivimäki • \\ G. David Batty
}

Received: 14 March 2012 / Accepted: 10 June 2012 /Published online: 8 July 2012

(C) The Author(s) 2012. This article is published with open access at Springerlink.com

\begin{abstract}
There is growing interest in the measurement of frailty in older age. The most widely used measure (Fried) characterizes this syndrome using five components: exhaustion, physical activity, walking speed, grip strength, and weight loss. These components overlap, raising the possibility of using fewer, and therefore making the device more time- and costefficient. The analytic sample was 5,169 individuals (1,419 women) from the British Whitehall II cohort study, aged 55 to 79 years in 2007-2009. Hospitalization data were accessed through English national records (mean follow-up 15.2 months). Age- and
\end{abstract}

Electronic supplementary material The online version of this article (doi:10.1007/s11357-012-9446-2) contains

supplementary material, which is available to authorized users.

K. Bouillon $(\bowtie) \cdot$ S. Sabia $\cdot$ M. Jokela $\cdot$

A. Singh-Manoux $\cdot$ M. J. Shipley $\cdot$ M. Kivimäki

G. D. Batty

Department of Epidemiology and Public Health,

University College London,

1-19 Torrington Place,

London WC1E 6BT, UK

e-mail: kim.bouillon.09@ucl.ac.uk

M. Jokela

Institute of Behavioural Sciences, University of Helsinki,

Helsinki, Finland

C. R. Gale

MRC Lifecourse Epidemiology Unit,

University of Southampton,

Southampton, UK sex-adjusted Cox models showed that all components were significantly associated with hospitalization, the hazard ratios (HR) ranging from 1.18 (95\% confidence interval $=0.98,1.41)$ for grip strength to 1.60 $(1.35,1.90)$ for usual walking speed. Some attenuation of these effects was apparent following mutual adjustment for frailty components, but the rank order of the strength of association remained unchanged. We observed a dose-response relationship between the number of frailty components and the risk for hospitalization [ 1 component $-\mathrm{HR}=1.10(0.96$, $1.26) ; 2-\mathrm{HR}=1.52(1.26,1.83) ; 3-5-\mathrm{HR}=2.41$ 
$(1.84,3.16), P$ trend $<0.0001]$. A concordance index used to evaluate the predictive power for hospital admissions of individual components and the full scale was modest in magnitude (range 0.57 to 0.58 ). Our results support the validity of the multi-component frailty measure, but the predictive performance of the measure is poor.

Keywords Frail elderly · Frailty · Validation .

Prediction · Cohort study $\cdot$ Hospitalization

\section{Introduction}

Frailty is a clinically recognized geriatric syndrome characterized by age-related declines in functional reserves across an array of physiologic systems (Fried et al. 2001). In older adults, it is associated with multiple adverse health outcomes such as falls, fracture, disability, hospitalization, and mortality (Cawthon et al. 2007; Fried et al. 2001). There is evidence that frailty may be prevented (Boyd et al. 2009; Tan et al. 2009) and perhaps even reversed with appropriate intervention (Faber et al. 2006; Kenny et al. 2010; Peterson et al. 2007; Srinivas-Shankar et al. 2010).

Recent systematic literature reviews identified more than 20 frailty measures (de Vries et al. 2011; Sternberg et al. 2011), among which that developed by Fried and colleagues (Fried et al. 2001) is the most widely utilized. Comprising five components - weight loss, exhaustion, low physical activity, slow walking speed at usual pace, and low grip strength - this scale has been validated against subsequent health outcomes in a series of studies drawn from a range of diverse populations (Al Snih et al. 2009; Avila-Funes et al. 2008; Bandeen-Roche et al. 2006; Cawthon et al. 2007; Ensrud et al. 2007; Fairhall et al. 2011; Kiely et al. 2009; Kulminski et al. 2008; Rochat et al. 2010; Romero-Ortuno et al. 2010; Seematter-Bagnoud et al. 2010; Wong et al. 2010; Woods et al. 2005).

While it is assumed that the measurement of frailty needs to include multiple components, these inevitably overlap. Using fewer components would be more timeand cost-efficient. Although studies using the Fried frailty scale have generally shown that the greater the number of frailty components used the higher the risk of a given adverse health outcome (Avila-Funes et al. 2008; Bandeen-Roche et al. 2006; Cawthon et al. 2007; Ensrud et al. 2008; Fried et al. 2001; Kulminski et al. 2008), it remains unclear whether all components of the scale contribute to associations with health outcomes or whether some of them are redundant. Accordingly, for the first time to our knowledge, we compared the prediction accuracy of multi-component measures of frailty for total hospitalizations with a single-component measure.

\section{Materials and methods}

Study sample

The Whitehall II study is an ongoing, cohort study in which 10,308 (67 \% men) London-based British civil servants aged 35-55 years were recruited in 1985 (Marmot and Brunner 2005). The first examination (phase 1), which took place during 1985-1988, comprised a clinical examination and self-administered questionnaire. Subsequent phases of data collection have alternated between postal questionnaire alone [phases 2 (1988-1990), 4 (1995-1996), 6 (2001) and 8 (2006)], and postal questionnaire accompanied by a clinical examination [phases 3 (1991-1993), 5 (19971999), 7 (2002-2004) and 9 (2007-2009)].

For the current analyses, we used data drawn from phase 9 when frailty was first measured; this therefore represents our "baseline" for the present analyses. Of 10,308 study members at recruitment, 6,761 participated at phase 9, 2,588 were non-responders, 954 had died and the vital status of five was unknown. Of the 6,761 participants at phase 9, complete data for the frailty components and hospitalizations were available for 5,169 (74\% men). This constituted the study sample. The flow of participants through the study is depicted in Fig. 1.

Ethical approval for the Whitehall II study was obtained from the University College London Medical School Committee on the ethics of human research.

\section{Operationalization of frailty measure}

The Fried frailty measure comprises the following components (Fried et al. 2001):

1. Exhaustion: defined using two items drawn from the Center for Epidemiology Studies-Depression (CES-D) scale (Radloff 1977): "I felt that everything I did was an effort in the last week" and "I could not get going in the last week". If participants answered "occasionally or moderate amount of the time 
Fig. 1 Flow of study participants through the Whitehall II study, UK, 1989-2010

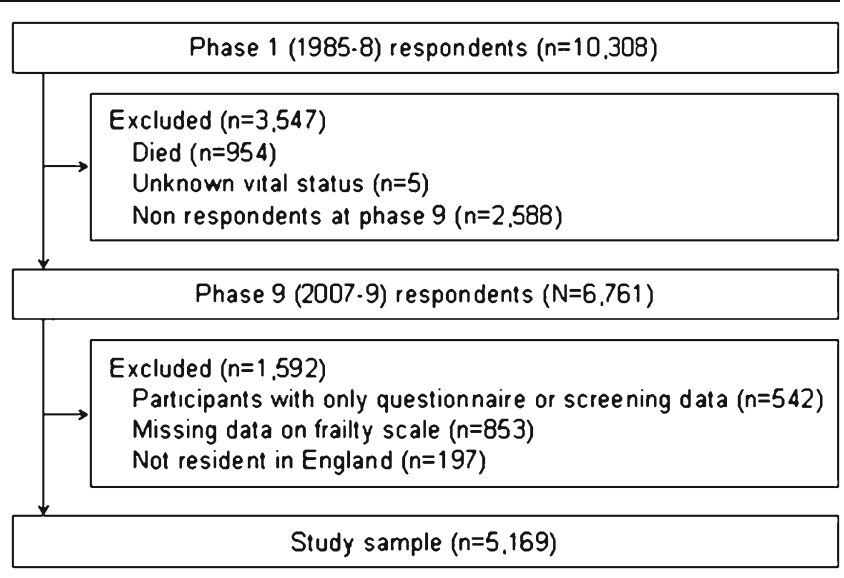

(3-4 days)" or "most or all of the time (5-7 days)" to either of these items, they were categorized as exhausted. If they answered "rarely or none of the time ( $<1$ day)" or "some or a little of the time (1-2 days)", they were categorized as not exhausted.

2. Physical activity: based on a modified version of the Minnesota leisure-time physical activity questionnaire (Folsom et al. 1985; Singh-Manoux et al. 2005) which ascertains the frequency and duration of participation in 20 different activities (e.g., running, cycling, other sports, housework, and gardening activities). Total hours per week were calculated for each activity and a metabolic equivalent (MET) value was assigned to each based on an existing compendium (Ainsworth et al. 1993). Energy expenditure (kcal/week) was calculated for each participant; low levels of physical activity were denoted by an expenditure of $<383 \mathrm{kcal} /$ week (men) and 270 (women) (Fried et al. 2001).

3. Walking speed: based on the duration of walking a distance of 8 - $\mathrm{ft}(2.4 \mathrm{~m})$ at usual pace. Established cut-offs are based on results for a $15-\mathrm{ft}(4.6 \mathrm{~m})$ walking test (Fried et al. 2001). Accordingly, following recomputation, participants were categorized as having slow walking speed when time to walk 8 -ft was $\geq 3.73$ s (for men with height $\leq 173 \mathrm{~cm}$ or women with height $\leq 159 \mathrm{~cm}$ ) or $\geq 3.20 \mathrm{~s}$ (for men with height $>173 \mathrm{~cm}$ or women with height $>159 \mathrm{~cm})$.

4. Grip strength: measured in kilograms using the Smedley hand grip dynamometer. Categorizations were stratified by gender and body mass index (BMI) (Fried et al. 2001). For men, low grip strength was $\leq 29 \mathrm{~kg}\left(\mathrm{BMI} \leq 24 \mathrm{~kg} / \mathrm{m}^{2}\right), \leq 30$ (BMI 24.1-28), and $\leq 32$ (BMI $>28$ ). For women, low grip strength was $\leq 17$ (BMI $\leq 23), \leq 17.3$ (BMI 23.1-26), $\leq 18$ (BMI 26.1-29), and $\leq 21$ (BMI $>29$ ).

5. Weight loss: Prior definitions of weight loss in the context of frailty have defined it as being unintentional and $5 \%$ or more over the previous year (Fried et al. 2001). We did not have weight loss in the previous year, so we instead utilized a cut-off of $10 \%$ in accordance with that in the Women's Health Aging Study-I (Boyd et al. 2005).

A total frailty score was calculated by allocating a value of 1 to each of the above criteria, resulting in a range of 0 to 5. Participants were classified as frail if they had at least three out of five of the frailty components, as pre-frail if they had 1-2, and as non-frail if they had none of these components.

\section{Outcome}

Information on the first hospitalization was prospectively ascertained from phase 9 (October 10, 2007) to January 31, 2010 by linkage of study members to the Hospital Episode Statistics (HES), a data registry including information on all admissions to National Health Service hospitals in England (The NHS Information Centre for health and social care 2011).

\section{Statistical analysis}

Incidence curves for hospitalization according to frailty status were produced using Kaplan-Meier plots (Kaplan and Meier 1958) and the log-rank test (Peto and Peto 1972). Having first ascertained that the proportional hazards assumptions had not been violated, hazard ratios (HR) and accompanying $95 \%$ confidence intervals (CI) 
for the associations of frailty (and its individual components) with all hospitalizations combined were computed using Cox proportional hazard regression models (Cox 1972). Given that there was no evidence that the relation between frailty and hospitalization was modified by gender or age (all $P$ values for interaction $>0.45$ ), data were pooled and adjusted for age and gender.

We first examined whether individual frailty markers were associated with the risk of hospitalization. Second, in order to explore whether a single component was responsible for generating the association between the overall frailty scale and the risk of hospitalization, we examined the cumulative effect of frailty markers in the prediction of hospitalization by creating a frailty score ranging from 0 (no frailty) to 5 . We then studied the effect of number and combinations of frailty components on the risk of hospitalization in two separate models. We also conducted a subgroup analysis among study participants who were negative for a given frailty component to estimate cumulative effects ( 0 to 4 ) of other frailty components in the prediction of adverse health outcomes. In all analyses, the reference group was that with no apparent frailty.

To evaluate the predictive power for each individual component and the full frailty scale, we calculated Harrell's $C$ concordance statistic (Harrell, Jr. et al. 1996), which is equivalent to the area under the curve statistic for receiver-operating characteristic plots but allows the calculation of concordance in each survival model. It estimates the concordance between the predicted failure order of a pair of subjects and the observed order. We split the analytic sample into "derivation" and "validation" datasets of equal size after stratification by age and sex. We then fitted age- and sex-adjusted models in the derivation dataset and evaluated the performance of the models in the validation dataset (Newson 2010).

Descriptive analyses and Cox proportional hazards models were performed using SAS version 9.1. Calculations of Harrell's $C$ concordance statistic were performed using Stata version 10.0.

\section{Results}

Study participants and missing data

Compared with participants alive at phase 9 but excluded (owing to unknown vital status, non-participation, missing data on the frailty scale, and living outside of England) $(n=4,153)$, people in the analytic sample $(n=$ $5,169)$ were on average 0.7 years younger, less likely to be female (27.5\% versus $39.7 \%$ ), and of low socioeconomic status (3.9\% versus $12.4 \%$ ).

In Table 1, we report the baseline characteristics of study members according to hospitalization. Of the 5,169 participants, $22.3 \%$ had at least one hospitalization episode during the follow-up (range 0.03 to 28.13 months; mean=15.17). In comparison with non-hospitalized participants, hospitalized participants were more likely to be older, positive for each frailty component, and classified as frail or pre-frail.

Association between frailty and future risk of hospitalization

Kaplan-Meier curves (Fig. 2) show that the cumulative hospitalization rate was higher among the frail group compared with their non-frail counterparts ( $P$ value for difference $<0.0001$ ). In age- and sexadjusted analyses, with the non-frail group as the referent, the frail group had an elevated hazard ratio for hospitalization of 2.40 [95\% confidence interval

Table 1 Baseline characteristics of the 5,169 study participants according to hospitalization during follow-up, Whitehall II study, UK, 2007-2010

\begin{tabular}{lllc}
\hline & \multicolumn{2}{l}{ Hospitalization } & \multirow{2}{*}{$P$ value $^{\mathrm{a}}$} \\
\cline { 2 - 3 } & $n(\%)$ & \\
\cline { 2 - 3 } & No & Yes & \\
\hline$N$ & 4,019 & 1,150 & \\
Age in years [mean (SD)] & $65.4(5.8)$ & $67.2(6.0)$ & $<0.0001$ \\
Women & $1,104(27.5)$ & $315(27.4)$ & 0.96 \\
Frailty components & & & \\
Exhaustion & $402(10.0)$ & $152(13.2)$ & 0.002 \\
Low physical activity & $875(21.8)$ & $301(26.2)$ & 0.002 \\
Slow walking speed & $340(8.5)$ & $163(14.2)$ & $<0.0001$ \\
Low grip strength & $373(9.3)$ & $139(12.1)$ & 0.005 \\
Weight loss & $135(3.4)$ & $54(4.7)$ & 0.03 \\
Frailty status & & & $<0.0001$ \\
Non-frail & $2,415(60.1)$ & $614(53.4)$ & \\
Pre-frail & $1,517(37.8)$ & $476(41.4)$ & \\
Frail & $87(2.1)$ & $60(5.2)$ & \\
\hline
\end{tabular}

${ }^{\text {a }} P$ value for heterogeneity except for frailty status where $P$ value is for trend 
Fig. 2 Kaplan-Meier curves showing the probability of future hospitalization by frailty status, Whitehall II study, UK, 2007-2010

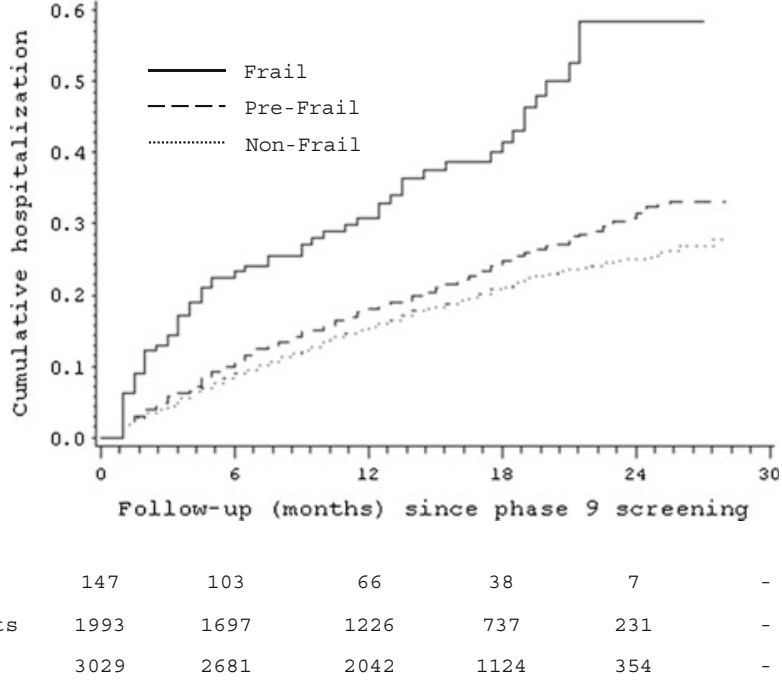

hospitalization. All five components were significantly associated with hospitalization, with the age- and sex-adjusted hazard ratios ranging from $1.18(95 \%$ $\mathrm{CI}=0.98,1.41)$ for grip strength to $1.60(95 \%$ $\mathrm{CI}=1.35,1.90)$ for walking speed. Some attenuation was apparent following adjustment for other components, but the rank order of the strength of association remained unchanged.
Table 2 illustrates the results of the association between individual frailty components and the risk of

$(\mathrm{CI})=1.83,3.14]$ while for the pre-frail group it was

Association between single components of frailty and future risk of hospitalization

Table 2 Hazard ratios (95\% confidence interval) for the association of individual frailty components with hospitalization $(n=5,169)$, Whitehall II study, UK, 2007-2010

adjustment for sex, age, exhaustion, physical activity, walking speed, grip strength, and weight loss

\begin{tabular}{|c|c|c|c|c|}
\hline & \multicolumn{2}{|c|}{ Hospitalization } & \multirow{3}{*}{$\begin{array}{l}\text { HR }[95 \% \mathrm{CI}] \\
\text { Sex- and age-adjusted }\end{array}$} & \multirow{3}{*}{$\begin{array}{l}\text { HR }[95 \% \mathrm{CI}] \\
\text { Fully adjusted }^{\mathrm{a}}\end{array}$} \\
\hline & \multicolumn{2}{|l|}{$N(\%)$} & & \\
\hline & No & Yes & & \\
\hline \multicolumn{5}{|c|}{ Exhaustion } \\
\hline No & $3,617(90.0)$ & $998(86.8)$ & 1 [Ref] & 1 \\
\hline Yes & $402(10.0)$ & $152(13.2)$ & $1.38[1.17,1.64]$ & $1.30[1.10,1.55]$ \\
\hline \multicolumn{5}{|c|}{ Low physical activity } \\
\hline No & $3,144(78.2)$ & $849(73.8)$ & 1 & 1 \\
\hline Yes & $875(21.8)$ & $301(26.2)$ & $1.26[1.10,1.44]$ & $1.19[1.04,1.36]$ \\
\hline \multicolumn{5}{|c|}{ Slow walking speed } \\
\hline No & $3,679(91.5)$ & $987(85.8)$ & 1 & 1 \\
\hline Yes & $340(8.5)$ & $163(14.2)$ & $1.60[1.35,1.90]$ & $1.52[1.28,1.80]$ \\
\hline \multicolumn{5}{|c|}{ Low grip strength } \\
\hline No & $3,646(90.7)$ & $1,011(87.9)$ & 1 & 1 \\
\hline Yes & $373(9.3)$ & $139(12.1)$ & $1.18[0.98,1.41]$ & $1.07[0.89,1.28]$ \\
\hline \multicolumn{5}{|c|}{ Weight loss } \\
\hline No & $3,884(96.6)$ & $1,096(95.3)$ & 1 & 1 \\
\hline Yes & $135(3.4)$ & $54(4.7)$ & $1.41[1.07,1.86]$ & $1.34[1.02,1.77]$ \\
\hline
\end{tabular}


Cumulative effect of frailty markers and the risk of hospitalization

Figure 3 shows a dose-response relationship between the risk of hospitalization and the number frailty components: the hazard ratios for hospitalization ranged from 1.10 (95 \% CI $=0.96,1.26)$ (any single frailty component) to 2.41 (95\% $\mathrm{CI}=1.84,3.16)(3-5$ frailty components). Figure 3 also displays hazard ratios and their $95 \%$ CIs for hospitalization according to different combinations of indicators included in the frailty scale when the scores were less than 3. Among study members with one frailty component only, the strength and the rank of association of each separate frailty component was slightly different from those reported in Table 2 where this estimation was carried out among the study participants with a frailty score of one or more. When we examined the possible combinations of two items from the frailty scale, there were very few study members with weight loss; therefore, three combinations were not represented. Two (low physical activity and slow walking speed; exhaustion and low physical activity) of a possible 10 combinations of those with two frailty indicators had very similar and strong associations (hazard ratios ranging from 1.80 to 1.83 ) with hospitalization.
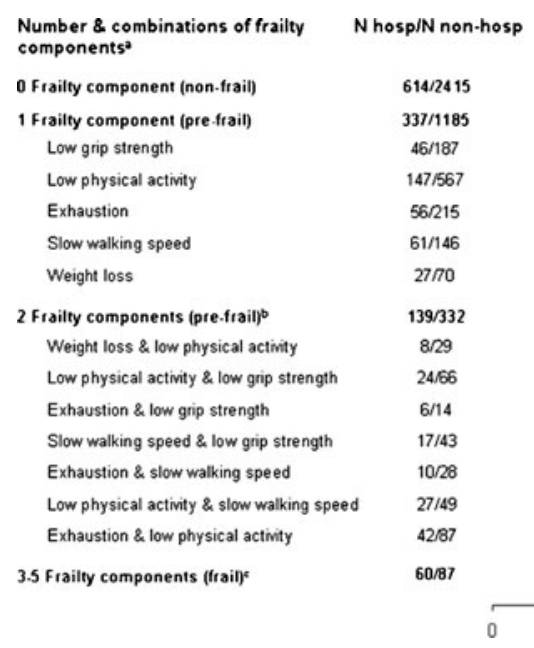

Fig. 3 Hazard ratios (95\% confidence interval) for the association of combinations of frailty components with later hospital-

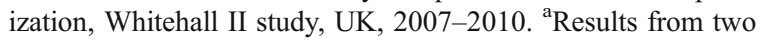
models: one with different combinations included in the model (diamonds); the other one with number of frailty components included in the model (squares). All analyses were adjusted for
In Table 3, we present the results of the association between the number of frailty components with the risk for hospitalization stratified by the presence of individual frailty components. Within each stratum, we still observed dose-response associations between the frailty score and the risk for hospitalization.

Predictive power of single- and multi-component measures for hospitalization

Harrell's $C$ concordance statistic for individual frailty components and the full frailty scale varied very little: $0.57(95 \% \mathrm{CI}=0.55,0.60)$ for grip strength and 0.58 $(95 \% \mathrm{CI}=0.56,0.61)$ for exhaustion and the full frailty scale. The difference of Harrell's concordance indices between pairs of individual components and the full scale was not statistically significant at conventional levels ( $P$ values $>0.06$; see Online appendix).

\section{Discussion}

The main objective of this study was to examine whether the five components included in the Fried frailty scale were equally related to the risk of hospitalization or whether one single component, or a combination, had the same utility as the full scale.

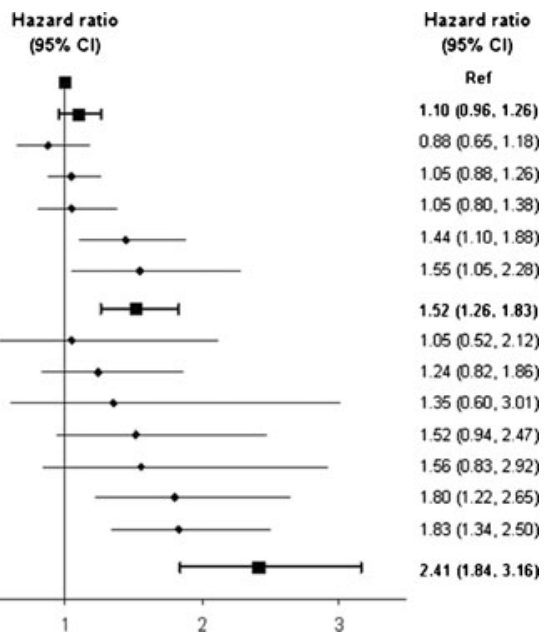

age at baseline and sex. The reference group was those with no frailty component. ${ }^{\mathrm{b}}$ Three combinations were not reported owing to too few hospitalizations: weight loss and slow walking speed $(n=0)$, weight loss and exhaustion $(n=2)$, and weight loss and low grip strength $(n=3)$. ${ }^{\mathrm{c} O w i n g}$ to low numbers, participants with three to five frailty components were collapsed 
Table 3 Hazard ratios (95\% confidence interval) for the association of number of frailty components with hospitalization, stratified by individual components, Whitehall II study, UK, 2007-2010

\begin{tabular}{|c|c|c|c|c|c|c|c|}
\hline & $N$ hosp & $N$ non-hosp & HR $[95 \% \mathrm{CI}]$ & & $N$ hosp & $N$ non-hosp & HR $[95 \% \mathrm{CI}]$ \\
\hline Exhaustion $=$ no & 998 & 3,617 & & Exhaustion $=$ yes & 152 & 402 & \\
\hline 0 & 614 & 2,415 & 1 [Ref] & 0 & 56 & 215 & 1 [Ref] \\
\hline 1 & 281 & 970 & $1.11[0.96,1.28]$ & 1 & 60 & 136 & $1.62[1.12,2.33]$ \\
\hline 2 & 79 & 196 & $1.40[1.10,1.77]$ & 2 & 24 & 39 & $2.30[1.41,3.74]$ \\
\hline $3-4$ & 24 & 36 & $2.09[1.39,3.16]$ & $3-4$ & 12 & 12 & $3.72[1.97,7.01]$ \\
\hline$P$ value for trend & & & 0.0001 & $P$ value for trend & & & $<0.0001$ \\
\hline $\begin{array}{l}\text { Low physical } \\
\text { activity = no }\end{array}$ & 849 & 3,144 & & $\begin{array}{l}\text { Low physical } \\
\text { activity }=\text { yes }\end{array}$ & 301 & 875 & \\
\hline 0 & 614 & 2,415 & 1 [Ref] & 0 & 147 & 567 & 1 [Ref] \\
\hline 1 & 190 & 618 & $1.14[0.96,1.34]$ & 1 & 101 & 231 & $1.52[1.17,1.96]$ \\
\hline 2 & 38 & 101 & $1.40[1.01,1.96]$ & 2 & 41 & 64 & $2.25[1.58,3.21]$ \\
\hline $3-4$ & 7 & 10 & $2.22[1.05,4.69]$ & $3-4$ & 12 & 13 & $3.61[2.00,6.55]$ \\
\hline$P$ value for trend & & & 0.005 & $P$ value for trend & & & $<0.0001$ \\
\hline $\begin{array}{l}\text { Slow walking } \\
\text { speed }=\text { no }\end{array}$ & 987 & 3,679 & & $\begin{array}{l}\text { Slow walking } \\
\text { speed }=\text { yes }\end{array}$ & 163 & 340 & \\
\hline 0 & 614 & 2,415 & 1 [Ref] & 0 & 61 & 146 & 1 [Ref] \\
\hline 1 & 276 & 1,039 & $1.05[0.91,1.21]$ & 1 & 54 & 124 & $1.13[0.78,1.63]$ \\
\hline 2 & 85 & 208 & $1.47[1.17,1.85]$ & 2 & 36 & 57 & $1.52[1.00,2.30]$ \\
\hline $3-4$ & 12 & 17 & $2.58[1.46,4.57]$ & $3-4$ & 12 & 13 & $2.46[1.32,4.58]$ \\
\hline$P$ value for trend & & & 0.0004 & $P$ value for trend & & & 0.004 \\
\hline $\begin{array}{l}\text { Low grip } \\
\text { strength }=\text { no }\end{array}$ & 1,011 & 3,646 & & $\begin{array}{l}\text { Low grip } \\
\text { strength }=\text { yes }\end{array}$ & 139 & 373 & \\
\hline 0 & 614 & 2,415 & 1 [Ref] & 0 & 46 & 187 & 1 [Ref] \\
\hline 1 & 291 & 998 & $1.15[1.00,1.32]$ & 1 & 50 & 128 & $1.58[1.06,2.36]$ \\
\hline 2 & 89 & 204 & $1.61[1.29,2.02]$ & 2 & 33 & 49 & $2.56[1.63,4.01]$ \\
\hline $3-4$ & 17 & 29 & $2.48[1.52,4.03]$ & $3-4$ & 10 & 9 & $4.93[2.47,9.84]$ \\
\hline$P$ value for trend & & & $<0.0001$ & $P$ value for trend & & & $<0.0001$ \\
\hline Weight loss $=$ no & 1,096 & 3,884 & & Weight loss $=$ yes & 54 & 135 & \\
\hline 0 & 614 & 2,415 & 1 [Ref] & 0 & 27 & 70 & 1 [Ref] \\
\hline 1 & 310 & 1,115 & $1.08[0.94,1.23]$ & 1 & 13 & 45 & $0.69[0.35,1.35]$ \\
\hline 2 & 126 & 287 & $1.59[1.31,1.92]$ & 2 & 10 & 13 & $2.09[0.99,4.39]$ \\
\hline $3-4$ & 46 & 67 & $2.33[1.72,3.16]$ & $3-4$ & 4 & 7 & $1.54[0.53,4.49]$ \\
\hline$P$ value for trend & & & $<0.0001$ & $P$ value for trend & & & 0.19 \\
\hline
\end{tabular}

Although the dose-response relationship between the number of frailty components and the risk of adverse health outcomes (Avila-Funes et al. 2008; BandeenRoche et al. 2006; Cawthon et al. 2007; Ensrud et al. 2008; Fried et al. 2001; Kulminski et al. 2008) is well known, our results add some novel findings to this literature. First, we show that all five frailty components - exhaustion, low physical activity, slow walking speed, low grip strength, and weight loss - are independently associated with hospitalization with none of them being redundant. Thus, these analyses support the hypothesis that several components are required to measure frailty (Fried et al. 2001; Rockwood 2005). Our results are consistent with those from a previous study (Rothman et al. 2008) where the authors found that slow walking speed was the strongest, and low grip strength the weakest, predictors of hospitalization.

Second, we formally tested the predictive performance of the individual frailty components compared with the full frailty scale. Harrell's $C$ concordance statistic varied between 0.57 and 0.58 ( 0.50 indicates that the prediction does not differ from chance), suggesting that neither the 
components nor the full scale were adequate prediction tools for hospitalization in the clinical settings. This probably indicates that frailty and its components capture only a limited range of the conditions leading to hospitalization. Third, the absence of difference in predictive performance between individual components and the full scale suggest that measuring only one component of frailty enables an equally precise prediction of hospitalization as the full scale; other analyses conducted in this study did not support this conclusion. Importantly, we found that within the group of individuals with a frailty component those who additionally had other components were up to 4.9 times more likely to experience hospitalization at follow-up compared with those with no additional frailty components. Thus, the frailty measure seemed to stratify risk even within the group of individuals with an individual frailty component.

The main strength of our study resides in using an objective and national database (British National Health Service) to derive our outcome. Therefore, it is unlikely to be subject to reporting bias. A limitation, shared with many studies in this field of research, is a departure from the original frailty scale. This was particularly the case with weight loss because weight in the previous year was not available in our study. As many studies on frailty, including ours, are analyses of existing cohorts primarily set up for other purposes, assessment of frailty components tends to differ between them. Nonetheless, effort should be made to use a standardized definition in order to allow direct comparisons of results between different populations. Furthermore, because our study sample consisted predominantly of white collar workers aged from 55 to 79 years (mean age $=65.8$ ), this may limit the generalizability of our findings.

In conclusion, our results indicate that a composite measure of frailty proposed by Fried is related to future risk of hospitalization but shows poor performance as a predictive tool. Much previous work in this domain is based on elderly individuals. That the frailty scale and its individual components are prospectively associated with hospitalization in our cohort, where participants were aged 55-79 years at baseline, suggests that the scale could be used to reliably monitor frailty status of adults in middle and early old age.

Acknowledgments All authors contributed to conception and design, and to analysis and interpretation of data, or wrote the first draft of the article and revised it critically for important intellectual content. All approve the final version to be published.

We thank all participating men and women in the Whitehall II Study; all participating Civil Service departments and their welfare, personnel, and establishment officers; the Occupational Health and Safety Agency; and the Council of Civil Service Unions. The Whitehall II Study team comprises research scientists, statisticians, study coordinators, nurses, data managers, administrative assistants, and data entry staff, who make the study possible.

Fundings This work was supported by grants from the Medical Research Council, UK; Economic and Social Research Council, UK; British Heart Foundation, UK; Health and Safety Executive, UK; Department of Health, UK; BUPA Foundation, UK; National Heart Lung and Blood Institute (R01HL036310), US; NIH: National Institute on Aging (R01AG013196; R01AG034454), US. GDB is a Wellcome Trust Fellow. MS is supported by the British Heart Foundation and MK is supported by the Academy of Finland, Finland.

Open Access This article is distributed under the terms of the Creative Commons Attribution License which permits any use, distribution, and reproduction in any medium, provided the original author(s) and the source are credited.

\section{References}

Ainsworth BE, Haskell WL, Leon AS, Jacobs DR Jr, Montoye HJ, Sallis JF, Paffenbarger RS Jr (1993) Compendium of physical activities: classification of energy costs of human physical activities. Med Sci Sports Exerc 25:71-80

Al Snih S, Graham JE, Ray LA, Samper-Ternent R, Markides KS, Ottenbacher KJ (2009) Frailty and incidence of activities of daily living disability among older Mexican Americans. J Rehabil Med 41:892-897

Avila-Funes JA, Helmer C, Amieva H, Barberger-Gateau P, Le Goff M, Ritchie K, Portet F, Carriere I, Tavernier B, Gutierrez-Robledo LM, Dartigues JF (2008) Frailty among community-dwelling elderly people in France: the threecity study. J Gerontol A Biol Sci Med Sci 63:1089-1096

Bandeen-Roche K, Xue QL, Ferrucci L, Walston J, Guralnik JM, Chaves P, Zeger SL, Fried LP (2006) Phenotype of frailty: characterization in the women's health and aging studies. J Gerontol A Biol Sci Med Sci 61:262-266

Boyd CM, Xue QL, Simpson CF, Guralnik JM, Fried LP (2005) Frailty, hospitalization, and progression of disability in a cohort of disabled older women. Am J Med 118:1225-1231

Boyd CM, Ricks M, Fried LP, Guralnik JM, Xue QL, Xia J, Bandeen-Roche K (2009) Functional decline and recovery of activities of daily living in hospitalized, disabled older women: the Women's Health and Aging Study I. J Am Geriatr Soc 57:1757-1766

Cawthon PM, Marshall LM, Michael Y, Dam TT, Ensrud KE, Barrett-Connor E, Orwoll ES, Osteoporotic Fractures in Men Research Group (2007) Frailty in older men: prevalence, progression, and relationship with mortality. J Am Geriatr Soc 55:1216-1223 
Cox DR (1972) Regression models and life-tables. J R Stat Soc Ser B (Methodol) 34:187-220

de Vries NM, Staal JB, van Ravensberg CD, Hobbelen JS, Olde Rikkert MG, Nijhuis-van der Sanden MW (2011) Outcome instruments to measure frailty: a systematic review. [Review]. Ageing Res Rev 10:104-114

Ensrud KE, Ewing SK, Taylor BC, Fink HA, Stone KL, Cauley JA, Tracy JK, Hochberg MC, Rodondi N, Cawthon PM, for the Study of Osteoporotic Fractures Research Group (2007) Frailty and risk of falls, fracture, and mortality in older women: the study of osteoporotic fractures. J Gerontol A Biol Sci Med Sci 62:744-751

Ensrud KE, Ewing SK, Taylor BC, Fink HA, Cawthon PM, Stone KL, Hillier TA, Cauley JA, Hochberg MC, Rodondi N, Tracy JK, Cummings SR (2008) Comparison of 2 frailty indexes for prediction of falls, disability, fractures, and death in older women. Arch Intern Med 168:382-389

Faber MJ, Bosscher RJ, Chin APM, van Wieringen PC (2006) Effects of exercise programs on falls and mobility in frail and pre-frail older adults: a multicenter randomized controlled trial. Arch Phys Med Rehabil 87:885-896

Fairhall N, Sherrington C, Kurrle SE, Lord SR, Cameron ID (2011) ICF participation restriction is common in frail, community-dwelling older people: an observational crosssectional study. Physiotherapy 97:26-32

Folsom AR, Caspersen CJ, Taylor HL, Jacobs DR Jr, Luepker RV, Gomez-Marin O, Gillum RF, Blackburn H (1985) Leisure time physical activity and its relationship to coronary risk factors in a population-based sample. The Minnesota Heart Survey. Am J Epidemiol 121:570-579

Fried LP, Tangen CM, Walston J, Newman AB, Hirsch C, Gottdiener J, Seeman T, Tracy R, Kop WJ, Burke G, McBurnie MA, Cardiovascular Health Study Collaborative Research Group (2001) Frailty in older adults: evidence for a phenotype. J Gerontol A Biol Sci Med Sci 56:M146-M156

Harrell FE Jr, Lee KL, Mark DB (1996) Multivariable prognostic models: issues in developing models, evaluating assumptions and adequacy, and measuring and reducing errors. Stat Med 15:361-387

Kaplan EL, Meier P (1958) Nonparametric estimation from incomplete observations. J Am Stat Assoc 53:457-481

Kenny AM, Boxer RS, Kleppinger A, Brindisi J, Feinn R, Burleson JA (2010) Dehydroepiandrosterone combined with exercise improves muscle strength and physical function in frail older women. J Am Geriatr Soc 58:1707-1714

Kiely DK, Cupples LA, Lipsitz LA (2009) Validation and comparison of two frailty indexes: the MOBILIZE Boston study. J Am Geriatr Soc 57:1532-1539

Kulminski AM, Ukraintseva SV, Kulminskaya IV, Arbeev KG, Land K, Yashin AI (2008) Cumulative deficits better characterize susceptibility to death in elderly people than phenotypic frailty: lessons from the Cardiovascular Health Study. J Am Geriatr Soc 56:898-903

Marmot M, Brunner E (2005) Cohort Profile: the Whitehall II study. Int J Epidemiol 34:251-256

Newson RB (2010) Comparing the predictive power of survival models using Harrell's c or Sommers' D. Stata J 10:339-358

Peterson MJ, Sloane R, Cohen HJ, Crowley GM, Pieper CF, Morey MC (2007) Effect of telephone exercise counseling on frailty in older veterans: project LIFE. Am J Mens Health 1:326-334

Peto R, Peto J (1972) Asymptotically efficient rank invariant test procedures. J R Stat Soc Ser A (Gen) 135:185-207

Radloff LS (1977) The CES-D Scale. Appl Psychol Meas $1: 385-401$

Rochat S, Cumming RG, Blyth F, Creasey H, Handelsman D, Le Couteur DG, Naganathan V, Sambrook PN, Seibel MJ, Waite L (2010) Frailty and use of health and community services by community-dwelling older men: the Concord Health and Ageing in Men Project. Age Ageing 39:228233

Rockwood K (2005) What would make a definition of frailty successful? Age Ageing 34:432-434

Romero-Ortuno R, Walsh CD, Lawlor BA, Kenny RA (2010) A frailty instrument for primary care: findings from the Survey of Health, Ageing and Retirement in Europe (SHARE). BMC Geriatr 10:57

Rothman MD, Leo-Summers L, Gill TM (2008) Prognostic significance of potential frailty criteria. J Am Geriatr Soc 56:2211-2216

Seematter-Bagnoud L, Santos-Eggimann B, Rochat S, Martin E, Karmaniola A, Aminian K, Piot-Ziegler C, Bula CJ (2010) Vulnerability in high-functioning persons aged 65 to 70 years: the importance of the fear factor. Aging Clin Exp Res 22:212-218

Singh-Manoux A, Hillsdon M, Brunner E, Marmot M (2005) Effects of physical activity on cognitive functioning in middle age: evidence from the Whitehall II prospective cohort study. Am J Public Health 95:2252-2258

Srinivas-Shankar U, Roberts SA, Connolly MJ, O'Connell MD, Adams JE, Oldham JA, Wu FC (2010) Effects of testosterone on muscle strength, physical function, body composition, and quality of life in intermediate-frail and frail elderly men: a randomized, double-blind, placebocontrolled study. J Clin Endocrinol Metab 95:639-650

Sternberg SA, Wershof SA, Karunananthan S, Bergman H, Clarfield AM (2011) The identification of frailty: a systematic literature review. [Review]. J Am Geriatr Soc 59:2129-2138

Tan EJ, Rebok GW, Yu Q, Frangakis CE, Carlson MC, Wang T, Ricks M, Tanner EK, McGill S, Fried LP (2009) The longterm relationship between high-intensity volunteering and physical activity in older African American women. J Gerontol B Psychol Sci Soc Sci 64:304-311

The NHS Information Centre for health and social care (2011) Hospital Episode Statistics (HES) http://www.hesonli ne.nhs.uk. Accessed 25 January 2011

Wong CH, Weiss D, Sourial N, Karunananthan S, Quail JM, Wolfson C, Bergman H (2010) Frailty and its association with disability and comorbidity in a community-dwelling sample of seniors in Montreal: a cross-sectional study. Aging Clin Exp Res 22:54-62

Woods NF, LaCroix AZ, Gray SL, Aragaki A, Cochrane BB, Brunner RL, Masaki K, Murray A, Newman AB, Women's Health Initiative (2005) Frailty: emergence and consequences in women aged 65 and older in the Women's Health Initiative Observational Study. J Am Geriatr Soc 53:13211330 